\title{
Siembra directa: una alternativa para mejorar la sustentabilidad del cultivo de arroz (Oryza sativa L.) en el Perú
}

\section{Luz Rayda Gómez Pando 1 - Hugo Soplín Villacorta ${ }^{2}$ - Guillermo Sosa Peralta ${ }^{3}$ \\ Elizabeth Consuelo Heros Aguilar ${ }^{4 *}$}

Recepción: 24/04/2017

Aceptación: 16/06/2017

\section{Resumen}

En el Perú, el sistema de siembra de arroz al trasplante tiene altos costos de producción, y los riegos de inundación contribuyen a la emisión de metano. Existen otros sistemas de producción que mejorarían la sustentabilidad del cultivo. Este estudio tuvo como objetivo comparar los sistemas de siembra directa en seco (en hileras y al voleo) versus los sistemas de trasplante (sistema intensivo de cultivar arroz (SICA), trasplante en hileras y trasplante convencional), en la productividad del cultivar IR-43, y se realizó en condiciones del valle Jequetepeque, Trujillo-Perú. Se empleó el diseño de bloques completos al azar, con tres repeticiones. En las siembras directas en suelo seco se empleó la densidad de $80 \mathrm{Kg} \mathrm{ha}^{-1}$.

En los tratamientos del sistema al trasplante se colocaron los golpes a $0.25 \times 0.25 \mathrm{~m}$. En el sistema intensivo de cultivar arroz se utilizaron plántulas de 15 días de edad y en los trasplantes en hileras; y en el convencional, plántulas de 30 días. Los mayores rendimientos se obtuvieron en la siembra directa y el sistema intensivo de cultivar arroz que rindieron 6.27, 6.19 y $6.13 \mathrm{t} \mathrm{ha}^{-1}$, respectivamente. Los sistemas de trasplante en hileras y convencional alcanzaron los menores rendimientos con 4.17 y $4.14 \mathrm{t} \mathrm{ha}^{-1}$, respectivamente. El sistema intensivo de cultivar arroz fue manejado con modificaciones de su concepción original, aplicándose fertilizantes minerales y uso de herbicidas. Los resultados obtenidos indican que los sistemas de siembra directa son opciones viables para reemplazar, progresivamente, al sistema de trasplante.

Palabras clave: siembra directa en seco, trasplante, productividad, cultivar IR-43, Oryza sativa.

\begin{abstract}
In Peru, the sowing rice system to transplantation has high production costs and the flood risks contribute to the methane emission. There are other production systems that would improve the sustainability of the crops. The objective of this research is to compare the direct dry sowing (in rows and broadcast sowing) versus the transplant systems (intensive system of rice farming (ISRF), transplant in precision sowing and conventional transplant) in the farm productivity IR-43, and it was conducted in conditions of Jequetepeque valley, Trujillo - Peru. The design of randomized full blocks was used with three repetitions. The density of $80 \mathrm{~K}$ ha- 1 was implemented in the direct sowing in dry soil.

In the treatment of the transplantation system were placed blows at $0.25 \times 0.25 \mathrm{~m}$. In the intensive system of rice farming were used seedlings of 15 days of age and in the transplants in a row and in the conventional, seedlings of 30 days. The best profits were obtained in the direct seeding, and the intensive system of rice farming that produced respectively $6.27,619$ and $6.13 \mathrm{t}$ ha-1. The transplantation systems in rows and the conventional produced respectively the lowest profits with 4.17 and $4.14 \mathrm{t}$ ha-1. The intensive system of rice farming was conducted with modifications of its original conception; applying mineral fertilizers and use of herbicides. The obtained results indicate that the direct sowing systems are viable options to replace progressively to the transplant system.
\end{abstract}

Key words: direct dry seeding, transplant, productivity, farm IR-43, Oryza sativa.

1. Doctora en Ciencias Agrícolas, Profesora Principal, Departamento de fitotecnia, Facultad de Agronomía, Universidad Nacional Agraria La Molina, Lima-Perú; email: luzgomez@lamolina.edu.pe

2. PhD en Producción de semillas, Profesor Principal, Departamento de fitotecnia, Facultad de Agronomía, Universidad Nacional Agraria La Molina, Lima-Perú; email: husovi@lamolina.edu.pe

3. Magister Scientiae especialista en Estadística Aplicada, Coordinador, Dirección de Gestión de la Innovación Agraria, Instituto Nacional de Innovación Agraria INIA, Perú; email: gsosa@inia.gob.pe

4. Magister Scientiae, Profesora Asociada, Departamento de fitotecnia, Facultad de Agronomía, Universidad Nacional Agraria La Molina, Lima, Perú; email: lizheros@lamolina.edu.pe 


\section{Introducción}

El sistema de siembra dominante de arroz en el Perú es el trasplante, que se practica con riego de inundación en los valles arroceros de la costa y selva alta. Los cultivares que se siembran están adaptados a este manejo de agua y pertenecen a la sub especie Indica. Perú es el único país en la región que cultiva el arroz en el sistema al trasplante, en más del 75\% de su área, estimada en 300,000has (MINAGRI, 2015).

En el período de los años 2005-2014, las siembras en el ecosistema de riego aportaron el 93\% de la producción (MINAGRI, 2015). Los sistemas de siembra directa se realizaban en pequeñas áreas en la costa y en la selva baja, en las siembras al voleo de barriales ${ }^{5} \mathrm{y}$ al "tacarpo"6.

En los sistemas de trasplante, la gran demanda de mano de obra, los precios altos de jornales, la rentabilidad decreciente, el batido de los suelos, el alto consumo de agua y las emisiones de metano, contribuye al deterioro de la sustentabilidad del cultivo de arroz. El consumo de agua se estima entre 13,300 a $15,680 \mathrm{~m}^{-3} \mathrm{ha}^{-1}$ (ANA, 2012).

El sistema intensivo de cultivar arroz (SICA) ${ }^{7}$, una variante en el sistema de trasplante, fue desarrollado para las tierras altas en Madagascar en 1983, por el Padre Henri de Laula- nié para condiciones de riego de inundación intermitente; e incluye el uso de plántulas jóvenes (15 días de edad) y aplicación de materia orgánica. Los rendimientos reportados de los países que han ensayado el SICA como India, Indonesia, China han sido espectaculares, alcanzando hasta $15 \mathrm{t} \mathrm{ha}{ }^{-1}$, y está siendo utilizado en varios países para incrementar la producción (Stoop et al., 2002; Uphoff et al., 2002, Chapagnain et al., 2010, Balasubramanian et al., 2002).

El SICA se ha experimentado en el Perú, en el año 2003, en Rioja (selva alta con riego), con rendimientos de $11 \mathrm{t} \mathrm{ha}^{-1}$, a distanciamientos entre golpes de $0.25 \mathrm{x} 0.25 \mathrm{~m}$ y $10 \mathrm{t}$ ha-1con distanciamientos de 0.50x0.50m (Fernández, 2003).

La situación actual por efecto del cambio climático, demanda modificaciones en los sistemas de producción en el cultivo de arroz. Se necesitan sistemas de menor consumo de agua, mayor producción y de menor impacto ambiental. El consumo per-cápita de arroz es de 63.5Kg (MINAGRI, 2013). Para el año 2050 se estima una población de 40 millones (INEI, 2016), por lo cual la producción debe incrementarse en $28.4 \%$, que debe obtenerse mejorando el rendimiento por las limitaciones para incorporar nuevas tierras en el ecosistema de riego, tanto en costa como en selva.

5. Barriales son las playas del río Amazonas y sus afluentes que se forman al descender las aguas.

6. Tacarpo es la siembra directa en hoyos, que se practica en condiciones de secano.

7. Dentro del artículo, los investigadores se referirán a este sistema mediantes sus siglas. 
Los sistemas de siembra directa son las alternativas viables. En el Asia tropical y el Sureste Asiático hay una tendencia a la sustitución del sistema de trasplante por los sistemas de siembra directa (Cabangon, 2002; Pandey y Velasco, 2005; Rao et al., 2007). En el 2013, ya existía un 23\% de área sembrada en el sudeste asiático y un $28 \%$ en India, con dichos sistemas (Rao et al., 2007). Con ellos se disminuye el consumo de agua (Tabbal et al., 2004; IRRI, 2002), se obtienen las cosechas más temprano y no es necesario batir los suelos (Matloob et al., 2015). Las siembras se realizan en seco o en húmedo con sembradoras; también en láminas de agua con semilla germinada, en forma manual o aérea. En las áreas arroceras de las zonas templadas como Australia, California, áreas del mediterráneo (España, Italia), países de América Latina (Kumar y Ladha, 2011); y en Asia, se practican las siembras directas, por ser un método más eficiente de sembrar arroz (Naldang et al., 1996).

En este estudio se evalúa la influencia de los sistemas de siembra, en el rendimiento del cultivar IR-43, el más sembrado en el Perú, en las condiciones del valle Jequetepeque como una alternativa para mejorar la productividad y la sustentabilidad del cultivo de arroz en el Perú.

\section{Materiales y Métodos}

El estudio se realizó en el valle Jequetepeque, con coordenadas, $07^{\circ} 20^{\prime} 58^{\prime \prime}$ latitud sur y 70²7’26” longitud oeste a 106m.s.n.m. La temperatura más alta se presentó en el mes de marzo $\left(31.6^{\circ} \mathrm{C}\right)$ y la mínima en el mes de junio con $16.4^{\circ} \mathrm{C}$. La mayor radiación se presentó en el mes de marzo con 27389 Joules $\mathrm{m}^{-2}$; y la mínima radiación en el mes de junio con 22552 Joules $\mathrm{m}^{-2}$. Estas condiciones no fueron muy favorables para el desarrollo de las plantas que tuvieron altas temperaturas y baja radiación.

El suelo del área experimental es de origen aluvial, de textura franca, con contenido de materia orgánica baja (1.06\%), fósforo alto (24.6 ppm); disponibilidad media de potasio (141ppm). El pH es ligeramente ácido (6.5), que con la inundación se acerca a la neutralidad (7.0).

Para estudiar los métodos de siembra se utilizó el cultivar IR-43, desarrollado por el International Rice Research Institute (IRRI). Este cultivar en buenos ambientes y buen manejo agronómico alcanza rendimientos hasta de 13t ha-1, pero la susceptibilidad a Hydrellia wirthii, Chironomus xanthis, Tagosodes oryzicolus, que trasmite el virus de la hoja blanca, Sarocladium y Nakataea disminuyen los rendimientos que puedan descender hasta $5 \mathrm{t} \mathrm{ha}^{-1}$.

Los sistemas de siembra fueron cinco: dos métodos de siembra directa en seco (en hileras y al voleo) y tres de trasplante (SICA, trasplante en hileras y trasplante convencional). El área de la parcela fue de $36 \mathrm{~m}^{2}$; que estaban separadas por un bordo de $0.80 \mathrm{~m}$ de ancho y 
tuvieron riego independiente. El diseño empleado fue el de bloques completos al azar, con tres repeticiones. Los sistemas de siembra estudiados se detallan a continuación:

\begin{tabular}{|c|l|}
\hline Tratamientos & \multicolumn{1}{|c|}{ Sistemas de siembra } \\
\hline SDH & $\begin{array}{l}\text { Sistema de siembra di- } \\
\text { recta en hileras }\end{array}$ \\
\hline SDV & $\begin{array}{l}\text { Sistema de siembra di- } \\
\text { recta al voleo }\end{array}$ \\
\hline SICA & $\begin{array}{l}\text { Sistema intensivo de } \\
\text { cultivar arroz }\end{array}$ \\
\hline STH & $\begin{array}{l}\text { Sistema de trasplante } \\
\text { en hileras }\end{array}$ \\
\hline STC & $\begin{array}{l}\text { Sistema de trasplante } \\
\text { convencional }\end{array}$ \\
\hline
\end{tabular}

Figura 1. Sistemas de siembra estudiados.

En el tratamiento de siembra directa en hileras, las líneas de siembra se trazaron a $0.25 \mathrm{~m}$ de separación, colocándose la semilla seca en el fondo de la hilera, a una densidad de $80 \mathrm{Kg}$ $\mathrm{ha}^{-1}$. La siembra al voleo se hizo en forma manual y se enterró la semilla con un rastrillo. Luego se regaron las parcelas con ingreso lento del agua, para evitar el arrastre de la semilla y se aplicó una lámina de $0.15 \mathrm{~m}$. En los tratamientos de siembra directa, la fertilización se realizó a los 25 días después de la siembra, con $120 \mathrm{Kg} \mathrm{N}$ ha ${ }^{-1}$ como urea, más $60 \mathrm{Kg}$ de $\mathrm{P}_{2} \mathrm{O}^{5} \mathrm{ha}^{-1}$ como fosfato di amónico y $60 \mathrm{Kg} \mathrm{K}_{2} \mathrm{O}$ ha $^{-1}$ como sulfato de potasio, voleados en lámina de agua.
Para el tratamiento de sistema de trasplante SICA se realizó un almácigo especial de camas elevadas en hileras a $0.10 \mathrm{~m}$ de separación con semilla seca. La siembra se realizó el 15 de enero del año 2016 y se fertilizó a los ocho días con $100 \mathrm{Kg} \mathrm{N}^{-1}$ como sulfato de amonio, en lámina de agua. A los 15 días de la siembra se realizó el trasplante (30 de enero), en lámina delgada de agua $(0.05 \mathrm{~m})$, colocando una plántula por golpe a $0.25 \times 0.25 \mathrm{~m}$.

Para los demás tratamientos de trasplante, la siembra del almácigo se realizó también el 15 de enero del año 2016, empleándose $200 \mathrm{~g}$ de semilla $\mathrm{m}^{-2}$. Se voleó el almácigo con semilla germinada. La fertilización de almácigos para los tratamientos de trasplante en hileras y convencional, se realizó en forma fraccionada con $100 \mathrm{Kg} \mathrm{N} \mathrm{Na}^{-1}$ a los doce días después del voleo y $50 \mathrm{Kg} \mathrm{N}$ ha-1 a los ocho días después de la primera fertilización. El trasplante se realizó con plántulas de treinta días de edad (el 14 de febrero), colocando cuatro a cinco plántulas por golpe a $0.25 \times 0.25 \mathrm{~m}$, en lámina de agua. La fertilización de las parcelas se realizó a los quince días después del trasplante con las mismas dosis y fuentes que para las siembras directas.

Al finalizar el macollamiento, se aplicó $40 \mathrm{Kg} \mathrm{N}$ $\mathrm{ha}^{-1}$ en sulfato de amonio para uniformizar el crecimiento. $\mathrm{Al}$ inicio de la fase reproductiva se aplicó $120 \mathrm{Kg} \mathrm{N}$ ha-1en urea en lámina de agua. El control de malezas se realizó con herbicidas 
pre-emergentes, en el caso de los almácigos y siembra directa, empleándose bentiocarbo; en los trasplantes se aplicó butaclhor. Las plagas insectiles más importantes fueron Hydrellia wirthii, Tagosodes oryzicolus, que fueron controladas con aplicaciones de clothiniadin.

Entre las enfermedades, la causada por el virus de la hoja blanca (VHB) fue la más severa, por atacar desde el estadio de plántula hasta el estadio de macollamiento. Se realizó control químico al vector Tagosodes oryzicolus.

La cosecha se realizó en forma manual; la trilla fue "al azote" y el secado de los granos cosechados se hizo al sol en un área neta de $25 \mathrm{~m}^{2}$. Los rendimientos se ajustaron al $14 \%$ de humedad.

\section{Resultados y Discusión}

El análisis de variancia para rendimiento en grano mostró diferencias significativas entre los tratamientos (Tabla 1). Según la prueba de significación de Duncan al 0.05 (Tabla 2), los dos sistemas de siembra directa y el sistema intensivo de cultivar arroz (SICA) fueron estadísticamente similares, pero fueron sig- nificativamente superiores a los sistemas de trasplante en hileras y convencional que no fueron diferentes entre sí (ver Tabla 1).

Según los datos de Tabla 2, los sistemas de siembra directa rindieron en promedio 29\% más que los sistemas al trasplante. Las siembras directas rindieron en $6.23 \mathrm{tha}^{-1}$ vs $4.82 \mathrm{t}$ $\mathrm{ha}^{-1}$ de los sistemas de trasplante. En los sistemas de siembra al trasplante, los rendimientos más bajos fueron trasplante común - STC $\left(4.14 \mathrm{t} \mathrm{ha}^{-1}\right)$ y trasplante en hileras - STH $(4.17 \mathrm{t}$ $\left.\mathrm{ha}^{-1}\right)$, debido a que se trasplantaron plántulas de mayor edad, lo cual corrobora que la edad del almácigo es trascendental, pues a mayor edad de la plántula los rendimientos decrecen. La edad de la plántula al trasplante es un criterio importante en la producción de arroz porque contribuye a producir el número de macollos por golpe (Sanjeewanie et al., 2011). Además, Mobasser et al. (2007) señalan que los trasplantes utilizando plántulas con edad adecuada continúan su crecimiento normal, contrario a los que utilizan almácigos retrasados que influyen en pobres rendimientos (ver Tabla 2).

Tabla 1. Análisis de variancia del rendimiento en grano de arroz cáscara

\begin{tabular}{|l|c|c|c|c|c|c|}
\hline \multicolumn{1}{|c|}{ FV } & GL & S.C & C.M & F cal & Pr $>$ F & Nivel de significación \\
\hline Bloques & 2 & 0.20 & 0.10 & 0.17 & 0.85 & NS \\
\hline $\begin{array}{l}\text { Sistemas de } \\
\text { siembra }\end{array}$ & 4 & 15.02 & 3.75 & 6.14 & 0.01 & $*$ \\
\hline Error & 8 & 4.89 & 0.61 & & & \\
\hline Total & 14 & 20.11 & & & & \\
\hline
\end{tabular}


Tabla 2. Rendimiento en grano de arroz cáscara de los sistemas de siembra

\begin{tabular}{|l|c|}
\hline \multicolumn{1}{|c|}{ Tratamientos } & Rendimiento t ha-1 $\left(^{*}\right)$ \\
\hline Siembra directa en hileras - SDH & $6.27 \mathrm{a}^{\star *}$ \\
\hline Siembra directa al voleo - SDV & $6.19 \mathrm{a}$ \\
\hline Sistema intensivo de cultivar arroz - SICA & $6.13 \mathrm{a}$ \\
\hline Trasplante en hileras - STH & $4.17 \mathrm{~b}$ \\
\hline Trasplante común - STC & $4.14 \mathrm{~b}$ \\
\hline
\end{tabular}

${ }^{\star}$ Rendimientos ajustados al $14 \%$ de humedad. ${ }^{*}$ Dentro de la columna, los rendimientos con una misma letra, no son significativamente diferentes entre sí, según la prueba Duncan al 0,05\%.

De otro lado, la siembra de almácigos, con altas densidades de siembra $\left(200 \mathrm{~g} \mathrm{~m}^{-2}\right)$, determina que la competencia entre plántulas sea alta y genera un ambiente favorable para ataques de insectos (Hydrellia wirthii y Tagosodes oryzicolus) y proliferación de patógenos como el virus de la hoja blanca. El desarrollo del índice de área foliar fotosintético (IAF) se restringe por la competencia entre plantas. A distanciamientos cortos en los trasplantes, el número de hojas senescentes es mayor que a distanciamientos amplios por falta de luz (Welch et al., 2010).

En el SICA, el trasplante de una planta por golpe, con 15 días de edad, determina alto macollamiento y mayor número de panículas $\mathrm{m}^{-2}$, que en el trasplante común (TC); y en consecuencia, los rendimientos en grano son más altos: 6.13t ha-1 (Miah et al., 2004).

En el sistema de siembra directa en suelo seco en hileras o al voleo, los rendimientos son mayores que en trasplante, debido a que las plantas desarrollan sin alterar el sistema radícular; tienen mejor distribución espacial y los rendimientos están determinados principalmente por las panículas de los tallos principales más que de los macollos (Yoshida, 1981).

La relación entre producción de materia seca y rendimiento en grano fue positiva. Los rendimientos más altos de las siembras directas y SICA, que produjeron los más altos rendimientos en grano, fueron también las que alcanzaron las producciones más altas de materia seca (Figura 2). Esto concuerda con lo expresado por Naldang et al., (1996) y Chen et al., (2012), en el sentido de que las siembras directas producen más materia seca que los trasplantes. 


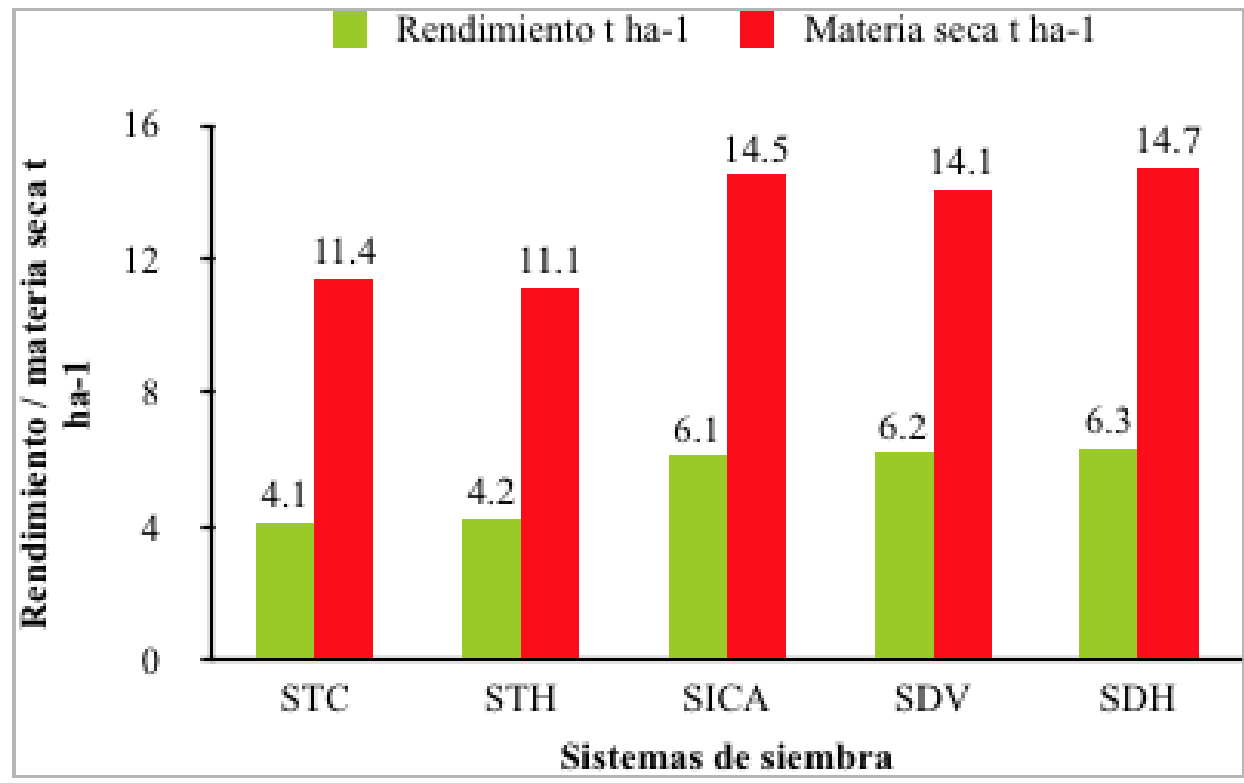

Figura 2. Relación entre rendimiento en grano y materia seca a la maduración por sistemas de siembra

El rendimiento biológico en los cereales es la producción de biomasa total de las plantas, y es una indicación del rendimiento fotosintético (Yoshida, 1981). El rendimiento biológico se relaciona con el rendimiento en grano por el índice de cosecha. En arroz no se incluyen las raíces en el rendimiento biológico. La relación entre el rendimiento de grano y el rendimiento biológico determina el índice de cosecha. Los índices de cosecha tuvieron los valores absolutos más altos en las siembras directas en hileras y voleo con 43 y $44 \%$. En el SICA el índice de cosecha fue de $42 \%$ (Figura 3 ).

Estos valores indican que, en siembra directa, se produjo algo más de grano que en SICA, por tonelada de materia seca producida. Estos resultados concuerdan con Fageria
(2007), quien postula que, con cultivares de buen vigor inicial, las siembras directas con buen manejo de nitrógeno podrían alcanzar altos rendimientos.

La relación entre macollamiento y rendimiento fue alta y positiva. En los sistemas de siembra directa, el número de macollos varió de 720 a 789 por $\mathrm{m}^{2}$. En los sistemas de trasplante, el SICA alcanzó el mayor número de macollos con 644 por $\mathrm{m}^{2}$ (ver figura 4).

Se debe indicar que en el sistema SICA se modificó varias de las recomendaciones originales (Makarim, et al., 2002). Se usó fertilizantes minerales en altos niveles de nitrógeno (240Kg N ha-1) como urea y no orgánicos, el uso de herbicidas y no el uso frecuente de desyerbos manuales, y se mantuvo el riego 


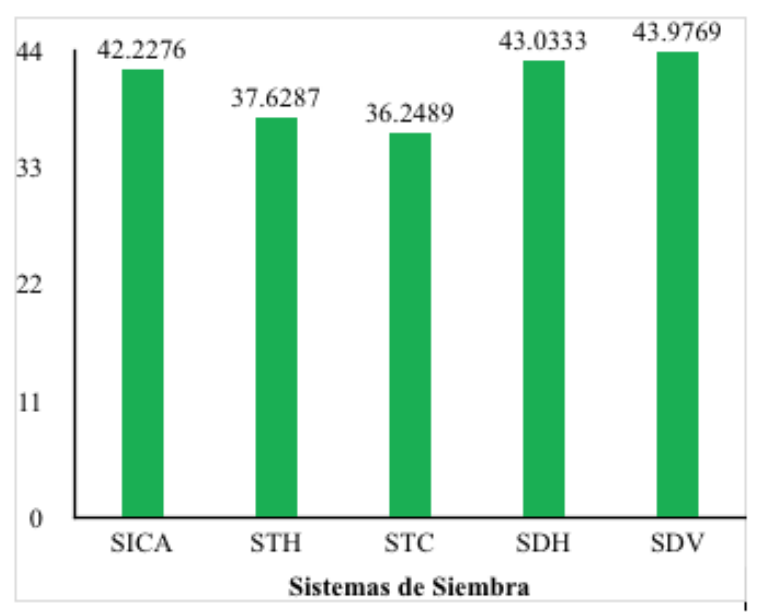

Figura 3. Índice de cosecha por sistema de siembra

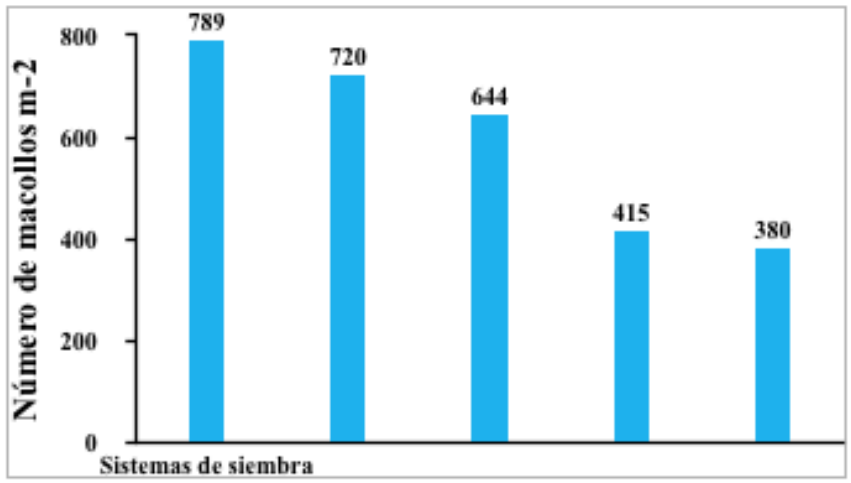

Figura 4. Macollos por metro cuadrado al máximo macollamiento por sistema de siembra.

con secas intermitentes en la fase vegetativa. Estas modificaciones han permitido alcanzar con SICA altos rendimientos en grano.

En los sistemas de trasplante común y en hileras, la edad de las plántulas trasplantadas fue de 30 días, que han reducido el macollamiento, en relación al trasplante SICA. La capacidad de macollamiento disminuye con el avance de la edad de las plántulas; las cuales, fisiológicamente viejas macollan menos (Bouman et al., 2002; Miah et al., 2002).
Los fertilizantes nitrogenados influyen en la capacidad de macollamiento. La disponibilidad de nitrógeno para las plantas influye en el desarrollo de los componentes de rendimiento, incluyendo el macollamiento (Fageria et al., 2003; Fageria, 2007), y en el ambiente biótico, como lo señalan Islam et al. (2007), que el sobreuso de nitrógeno susceptibiliza a las plantas al ataque de ciertas plagas y enfermedades. Los ataques de insectos y el virus de la hoja blanca por el aumento del vector, ocasiona muerte de macollos juveniles en las 
etapas tempranas del trasplante e infección en la etapa de macollamiento.

Las siembras directas, en sus diferentes modalidades, serían las opciones más adecuadas para la sustitución del trasplante por requerir menor uso de mano de obra y consumir menos agua (Kumar, y Ladha, 2011).

Los datos de la Tabla 3 indican que, para el cultivar IR-43 utilizado en este estudio, el periodo de siembra a la maduración fue de 143 días para los sistemas de siembra directa y de 152 días para los sistemas de trasplante; a excepción del SICA, en que las plántulas se trasplantaron inmediatamente después de la "saca" con todas sus raíces, sin rotura del sistema radícular como en el trasplante convencional; y maduró en 145 días. En cuanto a altura de planta SICA, obtuvo la estatura más alta $(98 \mathrm{~cm})$, entre los sistemas de trasplante, por la práctica de introducir en el suelo menor número de los internudos basales (2-3) durante la colocación de los "golpes" en el barro, mientras que en los trasplantes comunes se introducen los 4 a 5 internudos. Las siembras directas alcanzaron alturas entre 83 a $79 \mathrm{~cm}$. Gani et al. (2002), señalan que plántulas con edades de 7 a 14 días tienen mayor altura que las plántulas de 21 días (ver Tabla 3).

En los componentes de rendimiento no hubo significación estadística en el número de granos llenos por panícula, ni en el peso de 1000 granos. El número de granos llenos por panícula varió entre 158 para SICA y 121 granos para siembra directa en hilera. La esterilidad varió de 29 a 18\%, sin significación estadística. Las condiciones meteorológicas de luz y temperatura influyeron en el llenado de los granos.

Tabla 3. Días a la maduración, altura de planta e índice de cosecha en los diferentes sistemas de siembra

\begin{tabular}{|l|c|c|c|}
\hline \multicolumn{1}{|c|}{ Tratamientos } & $\begin{array}{c}\text { Maduración } \\
\text { (días) }\end{array}$ & $\begin{array}{c}\text { Altura de }\left(^{*}\right) \\
\text { planta } \mathbf{( c m})\end{array}$ & $\begin{array}{c}\text { Índice de }\left(^{*}\right) \\
\text { cosecha }(\%)\end{array}$ \\
\hline $\begin{array}{l}\text { Sistema intensivo de cultivar } \\
\text { arroz SICA }\end{array}$ & 145 & $98 \mathrm{a}$ & $42 \mathrm{a}$ \\
\hline Sistema de trasplante en hileras & 152 & $90 \mathrm{ab}$ & $38 \mathrm{a}$ \\
\hline Sistema de trasplante convencional & 152 & $93 \mathrm{bc}$ & $36 \mathrm{a}$ \\
\hline Sistema de siembra directa en hileras & 143 & $83 \mathrm{~cd}$ & $43 \mathrm{a}$ \\
\hline Sistema de siembra directa al voleo & 143 & $79 \mathrm{~d}$ & $\mathrm{~A}$ \\
\hline
\end{tabular}

*Dentro de cada columna, los datos que tienen una letra en común no son significativamente diferentes entre sí, según la prueba Duncan, al nivel de $5 \%$ de probabilidad. 
A falta de luz, las hojas inferiores se tornan senescentes, reduciéndose la intensidad de fotosíntesis de las plantas. Los días nublados, durante el crecimiento, afectan la formación de fotosíntatos para el llenado de los granos (Yoshida, 1981; Fageria, 2007).

El rendimiento de molinería se evaluó en términos de rendimiento en grano pulido entero y quebrado. Comercialmente el arroz en cáscara con $14 \%$ de humedad debe rendir $70 \%$ de arroz pilado, con pulido adecuado. En este estudio se observa que, entre los sistemas de siembra directa, SICA y el sistema de trasplante convencional, no hubo diferencias significa- tivas en cuanto a rendimiento de molinería el cual fluctuó entre $70.3 \%$ a $68.40 \%$. (Tabla 4).

El rendimiento en grano quebrado está dentro los estándares comerciales y varió de 11.9 a $15.9 \%$. El índice de trasluscencia es una característica genética (presencia de granos tizosos en la masa de granos pilados) que no ha sido influenciado por los sistemas de siembra, lo cual concuerda con lo señalado por Mandal et al. (2014), quienes señalan no haber encontrado diferencias significativas entre los métodos de trasplante convencional y SICA, en cuanto a esta característica.

Tabla 4. Rendimiento de molinería ${ }^{(1)}$, granos enteros y quebrados, e índice de trasluscencia ${ }^{(2)}$.

\begin{tabular}{|l|c|c|c|c|}
\hline \multicolumn{1}{|c|}{ Tratamientos } & $\begin{array}{c}\text { Rendimiento }\left(^{*}\right. \\
\text { de molinería } \\
(\%)\end{array}$ & $\begin{array}{c}\text { Granos }\left(^{*}\right) \\
\text { enteros (\%) }\end{array}$ & $\begin{array}{c}\text { Granos }\left(^{*}\right) \\
\text { quebrados } \\
(\%)\end{array}$ & $\begin{array}{c}\text { Índice } \\
\text { de }\left(^{*}\right)\end{array}$ \\
\hline $\begin{array}{l}\text { Sistema intensivo de cultivar } \\
\text { arroz SICA }\end{array}$ & $70.30 \mathrm{a}$ & $58.40 \mathrm{a}$ & $11.90 \mathrm{a}$ & $\begin{array}{c}\text { Traslus- } \\
\text { cencia } \\
(2)\end{array}$ \\
\hline $\begin{array}{l}\text { Sistema de siembra directa en } \\
\text { hileras }\end{array}$ & $69.74 \mathrm{a}$ & $55.67 \mathrm{ab}$ & $14.07 \mathrm{a}$ & $0.05 \mathrm{a}$ \\
\hline Sistema de siembra directa al voleo & $68.40 \mathrm{a}$ & $52.50 \mathrm{~b}$ & $15.90 \mathrm{a}$ & $0.09 \mathrm{a}$ \\
\hline Sistema de trasplante convencional & $68.13 \mathrm{a}$ & $55.87 \mathrm{ab}$ & $12.27 \mathrm{a}$ & $0.09 \mathrm{a}$ \\
\hline Sistema de trasplante en hileras & $65.77 \mathrm{~b}$ & $53.67 \mathrm{ab}$ & $12.10 \mathrm{a}$ & $0.13 \mathrm{a}$ \\
\hline
\end{tabular}

(1)Rendimiento de $100 \mathrm{~g}$ de arroz cáscara de tres repeticiones. ${ }^{\star}$ Dentro de cada columna, los datos que tienen una letra en común no son significativamente diferentes entre sí, según la prueba Duncan, al nivel de 5\% de probabilidad.

(2)Metodología CIAT, 1989 


\section{Conclusiones}

Las siembras directas en seco son factibles de usarse con ventajas, en relación al trasplante, por el mayor rendimiento en arroz en cáscara y la eliminación del batido del suelo. El periodo de siembra a maduración en la siembra directa tiene un acortamiento de 143 a 152 días en que madura las siembras al trasplante. La calidad molinera, expresada en rendimiento de grano entero pilado en la siembra directa, es similar a la calidad de arroz obtenida en el sistema de trasplante.

Los índices de cosecha son más altos en la siembra directa que en trasplante, obteniéndose más grano cáscara por tonelada de biomasa producida por hectárea.

\section{Referencias}

Autoridad Nacional del Agua (2012). Huella hídrica de arroz en el Perú. Recuperado de http://repositorio.ana.gob.pe/bitstream/ANA/546/1/ANA0000332.pdf

Balasubramanian, V. y Hill, J. E. (2002). Direct seedling of rice in Asia: Emerging issues and strategies research needs for the 21st century. In direct seeding: Research strategies and opportunities. Los Baños (Philippines): International Rice Research Institute, pp 15- 42

Bouman, B.; Hengsdig, K.; Hardy, B.; Bendraban, P.; Tuong, T. y Ladha, J. (2002). Water-wise rice production. Los Baños (Philippines): International Rice Research Institute, p. 356

Cabangon, R.; Tuong, T.; Tiak, E. y Abdullah, N. (2002). Increasing water productivity in rice cultivation: impact of the large-scale adoption of direct seeding in the Muda irrigation system. In 'Direct Seeding: Research Issues and Opportunities'; pp. 299-314

Centro Internacional de Agricultura Tropical (1989). Evaluación de la calidad culinaria y molinera del arroz; guía para ser usada como complemento de la unidad audiotutorial sobre el mismo tema, p. 73

Chapagain, T. y Yamaji, E. (2010). The effects of irrigation method, age of seedling and spacing on crop performance, productivity and water-wise rice production in Japan. E. Paddy Water Environ; vol. 8; pp. 81-90. doi:10.1007/s10333-009-0187-5

Chen, S.; Zhang, X.; Zhang, G.; Wang, D. y Xu, Ch. (2012). Grain yield and dry matter accumulation response to enhanced panicle nitrogen application under different planting methods (Oryza sativa L.). Australian Journal of Crop Science vol. 6(12); pp. 1630-1636. 
Chile, Ministerio de Agricultura (2015). Recuperado de http://frenteweb.minagri.gob.pe/ sisca/?mod=salida

Chile, Ministerio de Agricultura (2013). Arroz: principales aspectos de la cadena agroproductiva. Dirección General de Competitividad Agraria, p.37

Fageria, N. (2007). Yield physiology of rice. Journal of Plant Nutrition, vol. 30; pp. 843-879

Fageria N.; Slaton, N. y Baligar, V. (2003). Nutrient management for improving lowland rice productivity and sustainability. Advances in Agronomy, vol. 80; pp. 63-152.

Fernández, A. (2003). Ensayo de adaptabilidad del SRI y cinco variedades en Rioja. Recuperado de sri.cals.cornell.edu/countries/peru/perufnl.pdf.

Gani, A.; Rahman, A.; Rustam, D y Hengsdi, H. (2002). Synopsis of water managementexperiments in Indonesia.In: Water-wise rice production; pp. 29-38

Instituto Nacional de Información Estadística. Información estadística (2016).

Islam, Z.; Bagchi, B. y Hossain, M. (2007). Adoption of leaf color chart for nitrogen use efficiency in rice: Impact assessment of a farmer-participatory experiment in West Bengal, India. Field Crops Research, vol. 103(1); pp. 70-75

Kumar, V. y Ladha, J. (2011). Direct seeding of rice: Recent development and future research needs. Advance agronomy, Vol. III, Chapter Six. Recuperado de https://www.google. com/search?q=Kumar,+V.,+Ladha,+J.+2013.+Direct+seeding+of+rice:+Recent+devel opment+and + future + research + needs. $+\&$ ie $=u t f-8 \& o e=u t f-8 \& c l i e n t=$ firefox-b-ab\&gfe rd=cr\&ei=C21AWZzHEIiw8wewyZtY

Makarim, A.; Balasubramanian, V.; Zaini, Z.; Syamsiah, I.; Diratmadja, I.; Handoko, A.; Wardana, I. y Gani, A. (2002). System of Rice Intensification: evaluation of seedling age and selected components in Indonesia. In: Water wise rice production; pp.129-142.

Mandal, K.; Pramanick, M. y Bandopadhayay, P. (2014). Influence of crop establishment systems on yield and quality of rice grain and seeds of aromatic rice (Oryza sativa L.). International Journal of Applied Agricultural \& Horticultural Sciences (Abbr. Green Farming Int. J.), Vol,5 (6); pp. 951-955 
Matloob, A., Khalig, A., Singh, B. (2015). Weeds of direct seed in Asia Problems and opportunities in Advance in Agronomy, Vol. 130; pp. 291-336

Miah, M.; Talukder, M.; Sarkar, A. y Ansari, T. (2004). Effect of number of seedling per hill and urea supergranules on growth and yield of the rice cv. BINA Dhan 4. Journal of Biological Sciences, vol. 4(2); pp.122-129

Mobasser, H.; Tari, D.; Vojdani, M.; Abadi, M. y Eftekhari, A. (2007). Effect of Seedling Age and Planting Space on Yield and Yield Components of Rice (NedaVariety), Asian Journal of Plant Sciences, vol. 6(2); pp. 438-440

Naldang K.; Shu, F. y Nathabut, K. (1996). Growth of rice cultivars by direct seeding and transplanting under upland and lowland conditions. Field Crop Research, Vol. 48; pp. 115-123

Pandey, S.; Mortimer, M.; Wade, L.; Tuong, T.; Lopez, K. y Hardy, B. (2002). Direct seeding: Recent strategies and opportunities. Proceedings of the International Workshop on Direct Seeding in Asian Rice Systems: Strategic Research Issues and Opportunities; p. 383

Pandey S. y Velasco, L. (2005). Trend in crop establishment methods in Asia and research issues. In Rice is life: Scientific perspectives for the 21th century. International Rice Research Institute, Japan International Research Center for Agricultural Sciences, Tsukuba, Japan; pp. 178-181

Rao, A.; Jonhson, D.; Sivaprasad, B.; Ladha, J. y Mortimer, M. (2007). Weed managemet in direct-seeded rice. Adv. Agron. 93:153-255.

Sanjeewanie, G. y Ranamukhaarachchi, S. (2011). Study of age of seedlings at transplanting on growth dynamics and yiel of rice under alternating floodinf and suspension of irrigation of water management. Science and Technology, vol. 3(3): 76-88. ISSN: 2076-5061.

Stoop, W.; Uphoff, N. y Kassamc, A. (2002). A review of agricultural research issues raised by the system of rice intensification (SRI) from Madagascar: opportunities for improvingfarming systems for resource-poor farmers. Agricultural Systems, 71; pp. 249-274. Recuperado de https://www.zukunftsstiftung-landwirtschaft.de/.../StoopUphoffKa

Tabbal, D.; Bhinyand, S. y Bajan, B. (2005). The dry seeding technique for saving water in irrigated rice production system. In: Rice is life: Scientific perspectives for the $21^{\text {th }}$ century. Recuperado de large.stanford.edu/courses/2016/ph240/mccall1/docs/toriyama.pdf 
Uphoff, N. (2002). System of Rice Intensification (SRI) for enhancing the productivity of land labor and water. J.Agric.Resour.Manage, vol. 1(1); pp. 43-49

Welch, J.; Vincent, J.; Aufhammer, M.; Moya, P.; Dobermann, A. y Dawe, D. (2010). Rice yields in tropical/subtropical Asia exhibit large but opposing sensitivities to minimum and maximum temperatures. PNAS, vol. 107 (33):14562-14567.

Yoshida, S. (1981). Fundamentals of Rice Crop Science. International Research Institute, Philippines, p. 269 